\title{
Combination of the mTOR inhibitor RAD001 with temozolomide and radiation effectively inhibits the growth of glioblastoma cells in culture
}

\author{
HÉLÈNE BURCKEL ${ }^{1}$, ELODIE JOSSET ${ }^{1}$, JEAN-MARC DENIS ${ }^{2}$, JOHN GUEULETTE ${ }^{2}$, \\ JAKOBUS SLABBERT $^{3}$, GEORGES NOËL ${ }^{1,4}$ and PIERRE BISCHOFF ${ }^{1}$ \\ ${ }^{1}$ EA 3430, University of Strasbourg, Centre Paul Strauss, Strasbourg, France; \\ ${ }^{2}$ MIRO, Catholic University of Louvain, Brussels, Belgium; ${ }^{3}$ iThemba LABS, Somerset West, South Africa; \\ ${ }^{4}$ Radiotherapy University Department, Centre Paul Strauss, Strasbourg, France
}

Received September 3, 2014; Accepted October 2, 2014

DOI: $10.3892 /$ or.2014.3590

\begin{abstract}
The present in vitro study aimed to assess the effects of combining the mTOR inhibitor RAD001 and temozolomide (TMZ) together with irradiation by either low-linear energy transfer (LET) radiation ( $\gamma$-rays) or highLET radiation (fast neutrons) on the growth and cell survival of the human glioblastoma cell line U-87. We observed a strong decrease in cell proliferation along with a concomitant increase in cell death as a function of the radiation dose. As expected, high-LET radiation was more effective and induced more sustained damage to DNA than low-LET radiation. While RAD001 in association with TMZ induced autophagic cell death, additional combination with either type of radiation did not further increase its occurrence. On the contrary, apoptosis remained at a low level in all experimental groups.
\end{abstract}

\section{Introduction}

Glioblastoma multiforms (GBMs) are among the most aggressive types of cancer. They are very invasive, poorly operable and highly resistant to both conventional chemotherapy and radiotherapy. Hence, their prognosis remains poor and the survival rate of patients with GBM is extremely low due to the local evolution of the tumor. Resistance to anticancer drugs and radiation therapy (RT) results in large part from the incapacity of GBM cells to undergo apoptosis in response to these treatments (1).

Regarding RT, the use of high-linear energy transfer (LET) radiation instead of the low-LET radiation currently used in conventional therapy allows for more efficient anticancer treatmens due to ballistic distribution, inductor of hypoxic cell

Correspondence to: Dr Hélène Burckel, EA-3430, Université de Strasbourg, Centre Régional de Lutte contre le Cancer Paul Strauss, 3 Rue de la Porte de l'Hôpital, F-67065 Strasbourg Cedex, France E-mail: hburckel@strasbourg.unicancer.fr

Key words: glioblastoma, temozolomide, RAD001, irradiation death or both (2). On the other hand, standard chemotherapy of GBM principally consists in the administration of temozolomide (TMZ), an alkylating agent that is capable of crossing the hematoencephalic barrier. Moreover, molecularly targeted drugs are currently being evaluated in clinical trials, alone or combined with radiation, and the initial preclinical data are encouraging (3-7). This is the case of everolimus (RAD001), which acts as a potent inhibitor of the mechanistic target of rapamycin (mTOR), a key downstream protein kinase in the phosphatidylinositol 3-kinase (PI3K/AKT) pathway. The rationale for using RAD001 in cancer therapy is that mTOR expression is augmented with increasing grade of malignancy in a number of tumors including brain cancers (8) and that aberrant mTOR activation has been linked to cancer progression (9). This mTOR pathway can be hyperactivated by excessive stimulation via mutated growth factor receptors of ras (10). Considering their reciprocal advantages, combining high-LET radiation, classical and molecular-targeted drugs may thus represent a pleiotropic and potentially effective approach for the treatment of GBM.

In the present study, we investigated the effect of combining RAD001, TMZ and low-LET or high-LET radiation on the growth of U-87, a PTEN-deficient human GBM cell line (10). In our experiments, fast neutrons provided high-LET radiation. Although these particles are no longer used in radiation therapy in most countries, they still remain appropriate models for exploring the biological effects of high-LET radiation (11). We report here that a pronounced antiproliferative and cytotoxic effect resulted from this triple combination. As expected, at the same physical dose of radiation, fast neutrons were more efficient than $\gamma$-rays at depressing cell growth and at inducing cell death. We further sought to determine how cell death occurred in U-87 cells submitted to this triple combination.

\section{Materials and methods}

Treatments. RAD001 was provided by Novartis (Basel, Switzerland). A stock solution was dissolved in dimethylsulfoxide (DMSO) at $40 \mathrm{mM}$, stored at $-20^{\circ} \mathrm{C}$ and final dilutions were prepared in culture medium. TMZ was purchased from 
Sigma-Aldrich (Saint-Quentin Fallavier, France) and was also dissolved in DMSO in a $1 \mathrm{mM}$ stock solution. Both treatments, alone or together, were added to the cells $24 \mathrm{~h}$ before irradiation.

Cell culture. The human glioblastoma U-87 MG cell line was purchased from the American Type Culture Collection (\#HBT-14; ATCC; Rockville, MD, USA). Cultures were maintained at $37^{\circ} \mathrm{C}$ in a humidified atmosphere of $5 \% \mathrm{CO}_{2}$. Cells were grown in Dulbecco's modified Eagle's medium (DMEM; PAN Biotech GmbH, Dominique Dutscher, Brumath, France) supplemented with $10 \%$ fetal bovine serum (FBS; PAN Biotech $\mathrm{GmbH}), 1 \mathrm{mM}$ sodium pyruvate, $1 \mathrm{mM}$ non-essential amino acids and $50 \mu \mathrm{g}$ penicillin-streptomycin (PAN Biotech $\mathrm{GmbH}$ ). Disaggregation was carried out by a 10 -min incubation at $37^{\circ} \mathrm{C}$ with a solution of trypsin-EDTA (PAN Biotech $\mathrm{GmbH}$ ).

Irradiation. Cells, in their exponential growth phase, were exposed at room temperature to low-LET or high-LET radiation, $24 \mathrm{~h}$ after the addition of the treatment to the culture medium. Cells were contained in 6-well plates or in 96-well flat-bottomed microplates, filled with $4 \mathrm{ml}$ or $0.2 \mathrm{ml}$ culture medium, respectively. Low-LET irradiations were carried out with a ${ }^{137} \mathrm{Cs} \gamma$-irradiator (Biobeam GM8000; GSM GmbH, Leipzig, Germany) at the Paul Strauss Center (Strasbourg, France). The dose rate was $3.4 \mathrm{~Gy} / \mathrm{min}$ and doses ranged from 2 to $8 \mathrm{~Gy}$. For high-LET radiation, cells were exposed to a beam of $\mathrm{p}(65)+\mathrm{Be}$ neutrons produced by a Cyclone cyclotron at the Cyclotron Resources Center (CRC) (Louvain-la-Neuve, Belgium). The dose rate was usually $0.2 \mathrm{~Gy} / \mathrm{min}$ and doses ranged from 2 to $8 \mathrm{~Gy}$. A series of preliminary experiments with neutrons was conducted at iThemba Labs (Somerset West, South Africa). Each experiment was carried out at least three times. Control flasks were sham treated and/or irradiated.

Cell proliferation assay. The effects of the treatments, alone or combined, on the growth of U-87 cells were investigated using sulforhodamine B (SRB; Sigma-Aldrich) colorimetric assay. Cells were seeded at a density of $5 \times 10^{3}$ cells/well in $100 \mu 1$ in 96-well flat-bottomed plates (Falcon 3072). Subsequently, $100 \mu 1$ of different dilutions of RAD001 with/without TMZ were added $24 \mathrm{~h}$ later to quintuplicate wells. Cells were then irradiated and incubated at $37^{\circ} \mathrm{C}$ for 6 days. Then, they were fixed with $10 \%$ trichloroacetic acid (TCA; Sigma-Aldrich) for $1 \mathrm{~h}$ at $4^{\circ} \mathrm{C}$, washed five times with tap water, air dried and stained with $0.4 \%$ SRB in $1 \%$ acetic acid for $30 \mathrm{~min}$. SRB-stained cells were then dissolved in $200 \mu 110 \mathrm{mM}$ Tris-base (pH 10.5), and the absorbance of each well was measured at $565 \mathrm{~nm}$ using a Synergy ${ }^{\mathrm{TM}}$ HT microplate reader (Biotek, Colmar, France). Results are expressed in optical density (OD), after subtraction of the value for the blank (no cells).

Clonogenic survival assay. Cells were trypsinized and collected $24 \mathrm{~h}$ after irradiation in the presence or absence of treatment and enumerated using a Countess ${ }^{\circledR}$ Cell Counter (Countess; Invitrogen, Carlsbad, CA, USA). Then, they were seeded at an appropriate number and plated at two different dilutions into 6-well plates. The treatments were performed in triplicate and the experiments were repeated three times. Fifteen days later, the clones were stained with $0.05 \%$ crystal violet (Sigma-Adrich) in a 5\% ethanol solution, and positive colonies ( $>50$ cells) were scored. The plating efficiency was calculated by dividing the number of positive colonies that grew in the absence of treatment and irradiation by the number of cells that were seeded.

Apoptotic detection assay. Apoptotic cells were quantified 6 days after irradiation according to Riccardi and Nicoletti (12). Briefly, cells $\left(5 \times 10^{5}\right)$ were fixed in cold $70 \%$ ethanol for at least $1 \mathrm{~h}$, then they were washed in phosphate buffered saline [PBS; (pH 7.2)] and resuspended in $100 \mu \mathrm{l}$ of PBS containing $25 \mu \mathrm{g}$ of RNase A, 2 mM EDTA and $10 \mu \mathrm{g}$ of propidium iodide (PI). After incubation in the dark at $37^{\circ} \mathrm{C}$ for $30 \mathrm{~min}$, the fluorescence of 10,000 cells was analyzed using a FACScan flow cytometer and Cell Quest software (both from Becton Dickinson, San Jose, CA, USA). Cells with a sub-diploid DNA content were recorded as being apoptotic.

Autophagic detection assay. For autophagy determination 6 days after irradiation, we used the Cyto-ID ${ }^{\mathrm{TM}}$ Autophagy detection kit (Enzo Life Sciences, Plymouth Meeting, PA, USA) according to the manufacturer's instructions. This test measures autophagic vacuoles and monitors autophagic flux in live cells using a fluorescent cationic amphiphilic dye that selectively labels autophagic vacuoles. Briefly, cells $\left(5 \times 10^{5}\right)$ were washed in PBS (pH 7.2), and resuspended in $500 \mu \mathrm{l}$ of freshly diluted Cyto-ID ${ }^{\circledR}$ Green Detection Reagent to a final volume of $2 \mathrm{ml}$ with PBS, according to the manufacturer's instructions. The fluorescence of 10,000 cells was analyzed using a FACScan flow cytometer and Cell Quest software (Beckton Dickinson).

Determination of $\gamma$-H2AX foci. Cells were grown on microscopic glass slides placed in 6-well plates. Twenty-four hours after irradiation, the culture medium was removed and the slides were washed once with PBS. Fixation and permeabilization were carried out using $4 \%$ formaldehyde and $0.5 \%$ Triton, according to a standard procedure. Labeling was performed using a monoclonal mouse anti- $\gamma$-H2AX polyclonal antibody (clone JBW301; Upstate, Lake Placid, NY, USA). Coverslips were mounted in 4'-6-diamidino-2-phenylindole (DAPI)stained Vectashield (Abcys, Paris, France). The formation of $\gamma$-H2AX foci in nuclei were monitored by immunofluorescence microscopic imaging using an Olympus BH-2 fluorescence microscope equipped with a digital camera. Foci were counted in 50 cells in each condition.

Statistical analysis. All experiments were repeated at least three times independently. Statistical analyses were performed using the Prism 5 statistical software. Differences between the subgroups in term of cell counts, proportion of apoptotic and autophagic cells and foci number were evaluated using an ANOVA, together with a Student-Newman-Keuls test of all pairwise possible comparisons. Differences between subgroups were considered statistically significant at $\mathrm{P}<0.05$.

\section{Results}

Proliferation study. We first evaluated the ability of different concentrations of TMZ to decrease cell growth either alone, 


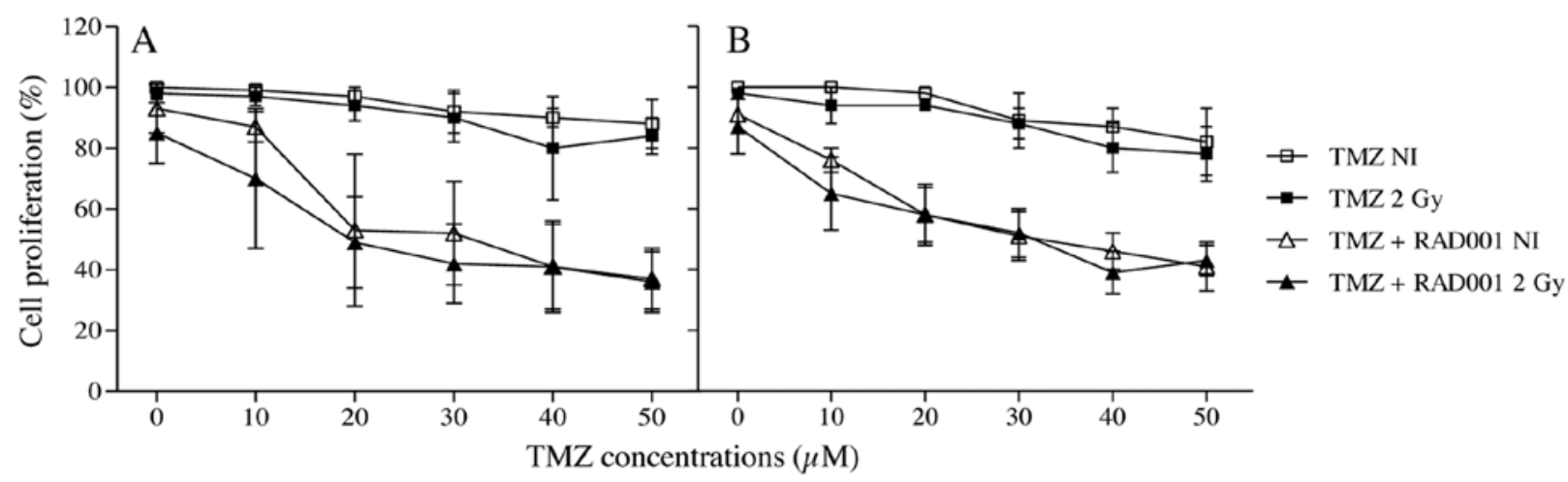

Figure 1. Effect of TMZ and the combination with RAD001 $(10 \mathrm{nM})$ on the growth of U-87 cells. TMZ was used at concentrations ranging from 10 to $50 \mu \mathrm{M}$. Cells were irradiated with (A) $\gamma$-rays or (B) fast neutrons at 2 Gy. Sulforhodamine B (SRB) tests were performed 6 days after irradiation, according to the protocol described in Materials and methods. Cell numbers are expressed as a percentage of proliferating cells to non-irradiated non-treated control cells. Error bars represent the standard deviation of the mean of quintuplicate determinations. Student-Newman-Keuls statistical tests were performed on four independent experiments. With $\gamma$ irradiation and neutron irradiation, the unirradiated association RAD001/TMZ was significantly different from TMZ with NI and $2 \mathrm{~Gy}\left({ }^{(* *} \mathrm{P}<0.001\right)$. At $2 \mathrm{~Gy}$, the association was also significantly different $\left({ }^{* *} \mathrm{P}<0.001\right)$ from TMZ with $\mathrm{NI}$ and $2 \mathrm{~Gy}$ whatever the irradiation type $(\gamma$ and neutron irradiation).

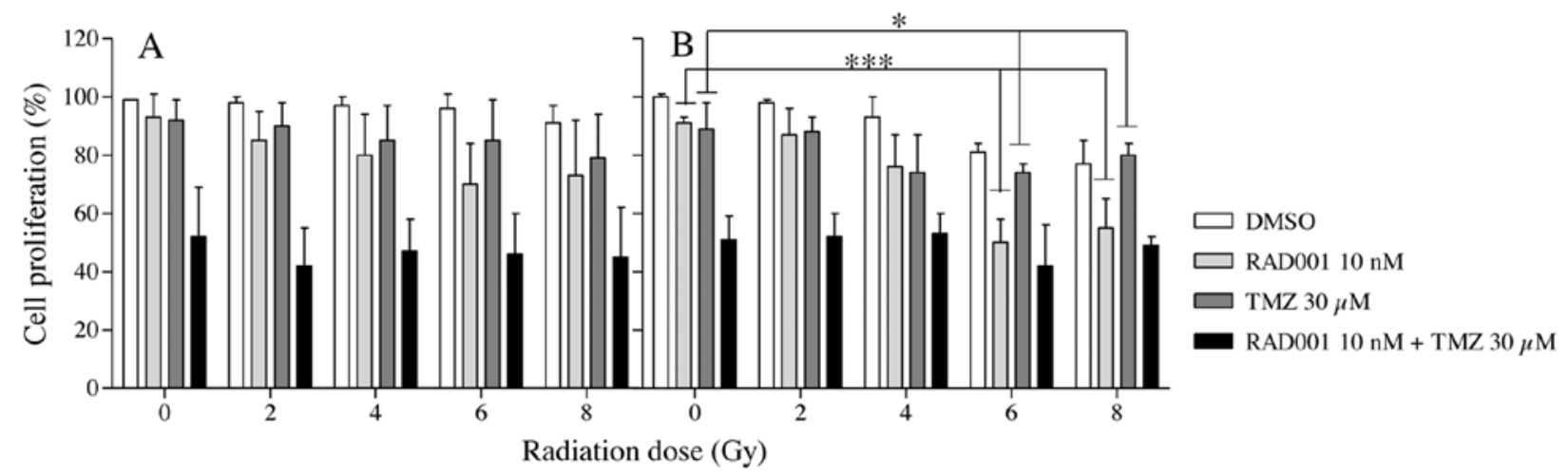

Figure 2. Effect of irradiation in the presence of RAD001 $(10 \mathrm{nM})$ and/or TMZ $(30 \mu \mathrm{M})$ on the growth of U-87 cells. Cells were irradiated by (A) $\gamma$-rays or (B) fast neutrons from 0 to 8 Gy. Sulforhodamine B (SRB) tests were performed 6 days after irradiation, according to the protocol described in Materials and methods. Cell numbers are expressed as a percentage of proliferating cells. DMSO represents the non-irradiated non-treated control. Error bars, standard deviation of the mean of five independent determinations. Student-Newman-Keuls statistical tests were performed on four independent experiments. The association RAD001+TMZ was significantly different $\left({ }^{* *} \mathrm{P}<0.001\right)$ from the control (DMSO), TMZ and RAD001 whatever the irradiation dose $(\gamma$ and neutron irradiation).

or combined with RAD001 and radiation using SRB assays. TMZ was added at increasing concentrations, ranging from 10 to $50 \mu \mathrm{M}$. Based on a previous study (13) RAD001 was used at a concentration of $10 \mathrm{nM}$. Cells were left unirradiated or irradiated at 2 Gy with both types of radiation. At this dose, $\gamma$-rays as well as neutrons alone failed to significantly reduce the growth of $\mathrm{U}-87$ cells, consistent with the known relative radioresistance of this cell line. As shown in Fig. 1, in the unirradiated cells, a slight decrease in the viable cell number was noted at higher concentrations of TMZ. Contrarily, in RAD001/TMZ co-treated unirradiated cells, a marked decrease in growth was noted. In $\gamma$-irradiated cells, a marked reduction in cell growth was obtained in the RAD001 co-treated cells, as a function of TMZ concentration (Fig. 1A), confirming previous results (13). Nevertheless, no significant differences were observed between both treatments with or without irradiation. Similar results were obtained in the neutron-irradiated cells (Fig. 1B).

In subsequent experiments, a unique TMZ concentration $(30 \mu \mathrm{M})$ was retained and cells treated with RAD001, TMZ and the combination RAD001/TMZ were irradiated at increasing doses of either $\gamma$-rays or neutrons. As shown in Fig. 2A, $\gamma$ radiation alone had no significant effect on cell growth. The identical outcome was obtained with RAD001or TMZ-treated U-87 cells whatever the irradiation dose. In contrast, in the RAD001/TMZ co-treated cells, a significant reduction in cell growth was obtained compared with the control (DMSO), RAD001 or TMZ independently from the delivered dose and the radiation type. In neutron-irradiated cells (Fig. 2B), no decrease in cell growth was observed in the treated cells, according to the radiation dose. In the RAD001treated cells, a marked decrease in proliferation was recorded from 2 to $6 \mathrm{~Gy}$. At the same dose range, in TMZ-treated cells, a slight decrease was observed. The most important effect in cell proliferation was recorded in the RAD001/TMZ co-treated cells without a difference from unirradiated to 8 Gy as obtained with $\gamma$-irradiated cells. To conclude, with or without exposure to either type of radiation, the combination RAD001/TMZ strongly depressed the proliferation of U-87 GBM cells.

Clonogenic survival study. In order to extend these results, colony-formation assays were carried out. With photons alone, we obtained a typical shoulder of the survival curve 


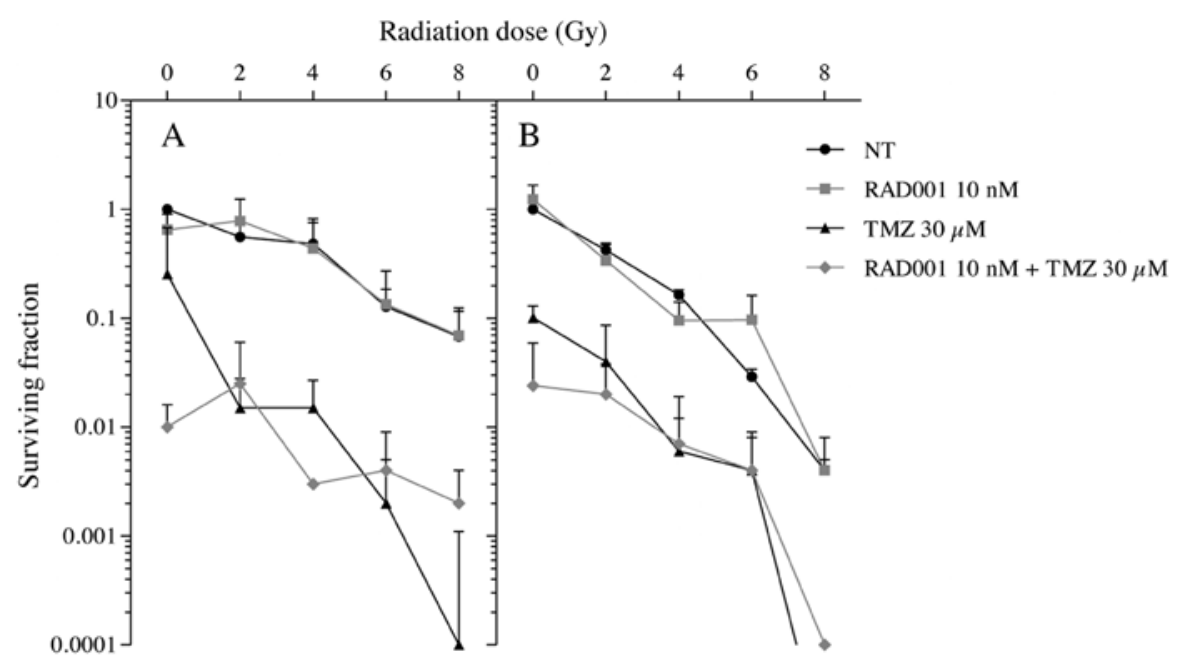

Figure 3. Clonogenic survival: surviving fraction of U-87 cells treated with RAD001 $(10 \mathrm{nM})$, TMZ $(30 \mu \mathrm{M})$ or with the combination and irradiated by (A) $\gamma$-rays or (B) fast neutrons. Radiation doses ranged from 0 to $8 \mathrm{~Gy}$. Fifteen days after irradiation, colonies were stained with crystal violet and colonies containing more than 50 cells were scored. Error bars, standard deviation of the mean of three independent determinations. $\mathrm{P}<0.05$.

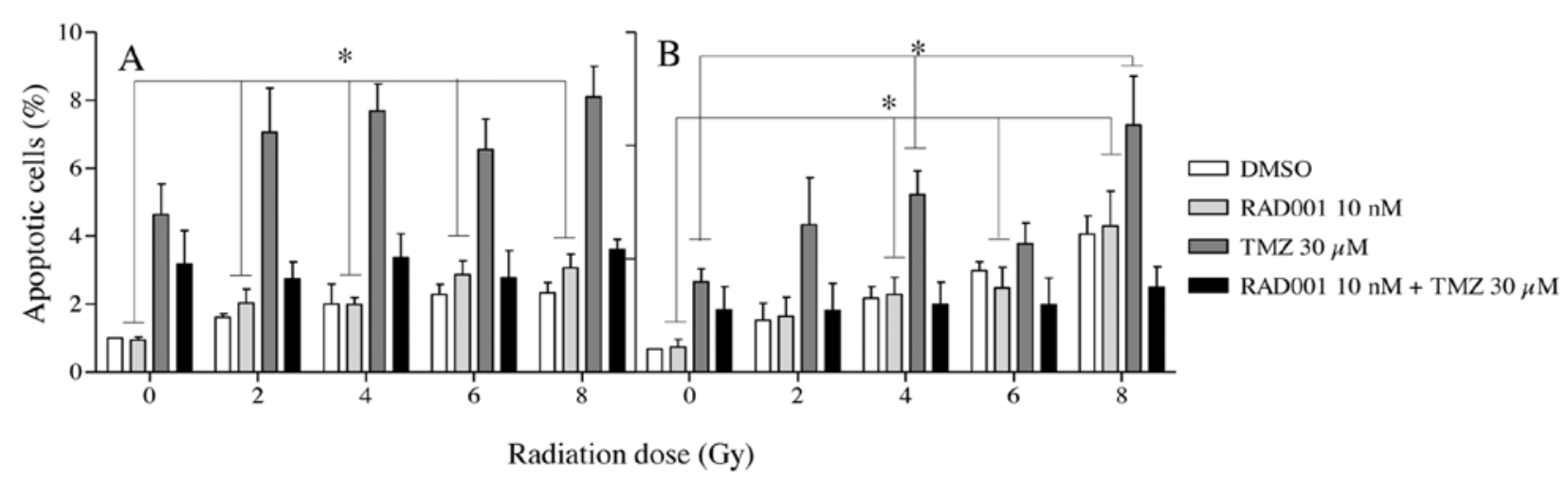

Figure 4. Percentage of apoptosis in U-87 cells, treated with RAD001 (10 nM) and/or TMZ (30 $\mu \mathrm{M})$ and irradiated by (A) $\gamma$-rays or (B) fast neutrons. Radiation dose ranged from 0 to $8 \mathrm{~Gy}$. Cells were labeled 6 days after irradiation with propidium iodide and the number of hypodiploid DNA-containing cells (expressed in percentage) were determined by flow cytometry. Error bars, standard deviation. Student-Newman-Keuls statistical tests were performed in three independent experiments. The association RAD001/TMZ was significantly different from TMZ ( ${ }^{* * *} \mathrm{P}<0.0001$ with $\gamma$-rays and ${ }^{*} \mathrm{P}<0.05$ with neutrons).

(Fig. 3A) although with neutrons alone, a sharp decrease in the number of colonies was observed (Fig. 3B) reaching a more efficient decrease in cell survival than with photons. Once combined with RAD001, no significant changes of this effect could be measured with both types of radiation. In contrast, in the TMZ-treated cells, a drastic decrease in the clonogenic survival was obtained as a function of the radiation dose whatever the radiation type. In irradiations with neutrons, the combination RAD001/TMZ was found to be much more efficient at reducing the clonogenic survival than with $\gamma$-rays.

Cell death induction. We next sought to determine what type of cell death was caused by treatment with TMZ, RAD001 and radiation, applied separately or in association. Percentages of cells undergoing apoptotic and autophagic cell death were determined at day 6 after irradiation. As shown in Fig. 4A and B, apoptosis levels were very low in all groups of treated cells, independently of the radiation type and dose. The highest values of apoptosis were recorded in the TMZ-treated cells, but apoptosis never exceeded $8 \%$. In cells submitted to the treatment RAD001/TMZ, these values were in fact decreased compared to those treated with TMZ alone.

Comparatively with apoptosis, autophagy levels were found to be higher in TMZ and RAD001/TMZ co-treated cells but again, irradiation failed to significantly increase the numbers of autophagic cells (Fig. 5A and B). It must be noted that in the neutron experiments, autophagy was always found to be higher in the TMZ unirradiated cells than in the $\gamma$-irradiated ones. Consequently, neither apoptosis nor autophagy could entirely account for the loss of survival in cells submitted to the triple combination.

$\gamma-H 2 A X$ activation and persistence. Since severe and irreparable damages to DNA, such as double-strand breaks (DSBs), are generally at the origin of cell death, foci corresponding to the persistent activation of $\gamma-\mathrm{H} 2 \mathrm{AX}$ in control and treated cells were recorded $24 \mathrm{~h}$ after the exposure to both types of radiation. As shown in Fig. 6A, in $\gamma$-irradiated cells, the foci number remained at a low level in all groups. Rather surprisingly, the radiation dose did not significantly increase their number. In contrast, foci numbers were slightly increased in 


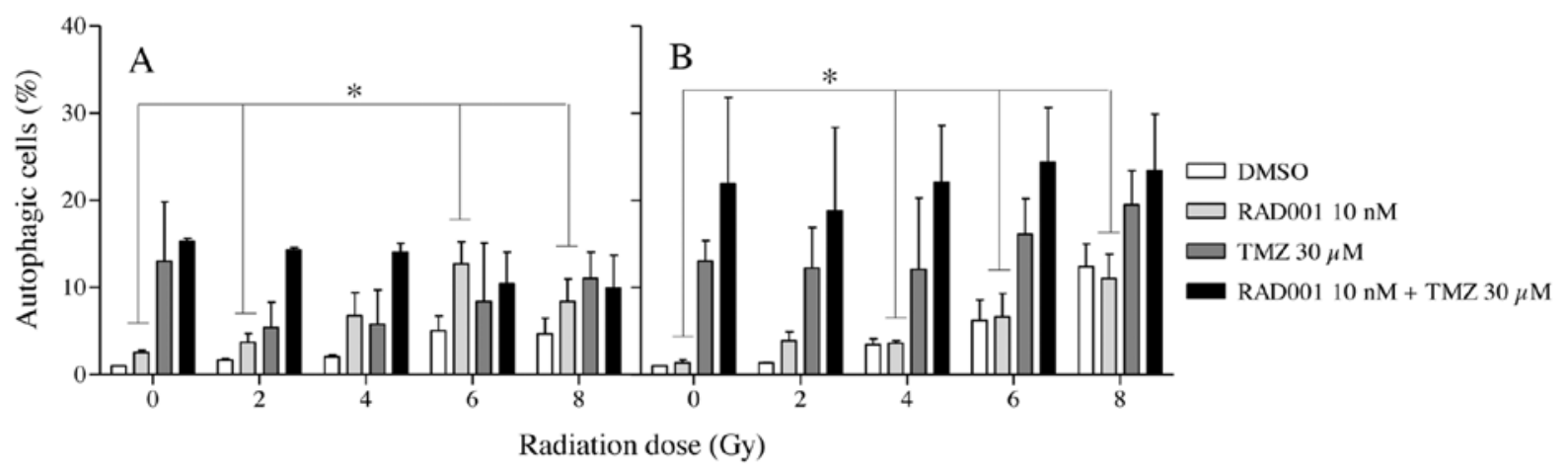

Figure 5. Induction of autophagy in U-87 cells, treated with RAD001 $(10 \mathrm{nM})$ and/or TMZ (30 $\mu \mathrm{M})$ and irradiated by (A) $\gamma$-rays or (B) fast neutrons. Radiation dose ranged from 0 to $8 \mathrm{~Gy}$. The percentage of cells in autophagy was determined by flow cytometry 6 days after irradiation, using the Cyto-ID ${ }^{\mathrm{TM}}$ autophagy detection kit according to the procedure described in Materials and methods. Student-Newman-Keuls statistical test was performed on three independent experiments. The association RAD001/TMZ was significantly different $($ (* $\mathrm{P}<0.001)$ from the control (DMSO), TMZ and RAD001 ( $\gamma$ and neutron irradiation).

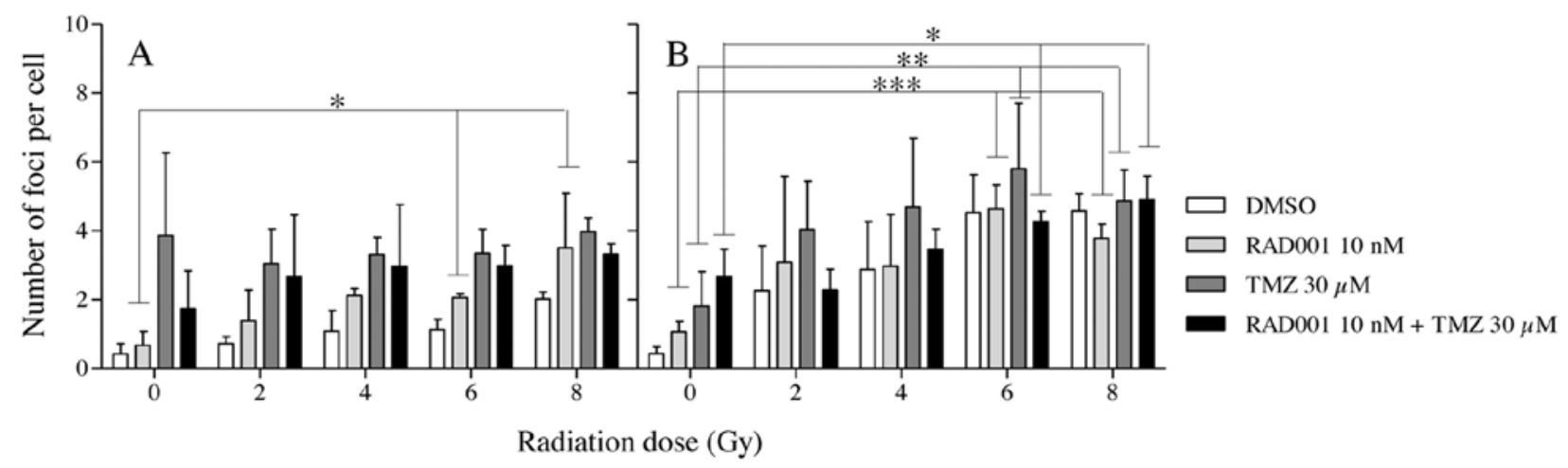

Figure 6. Effect of irradiation in the presence of RAD001 (10 nM) and/or TMZ (30 $\mu \mathrm{M})$ on the amount of $\gamma$-H2AX foci in U-87 cells. The number of foci of $\gamma$-H2AX/nucleus was the function of the dose and the radiation type: (A) $\gamma$-rays, (B) neutrons. Radiation dose ranged from 0 to 8 Gy. Foci were scored $24 \mathrm{~h}$ after irradiation. Error bars, standard deviation. Student-Newman-Keuls statistical tests were performed in three independent experiments.

the neutron-irradiated cells according to dose (Fig. 6B). TMZ alone or combined with RAD001 did not significantly affect their occurrence.

\section{Discussion}

We report the ability of a triple treatment associating RAD001, TMZ and irradiation with low-LET or high-LET radiation to reduce the growth and the survival of glioblastoma cells in vitro. Our results indicate that cell death occurred partly by autophagy, independently of the irradiation, and that apoptosis was not involved in cell destruction, consistent with our previous findings in the hepatocellular carcinoma cell line, SK-Hep-1 (14). These data suggest that other modes of cell death may contribute to the effectiveness of the combined treatment with RAD001, TMZ and irradiation. In addition, they showed that the radiation LET does not influence the outcome of this triple association treatment, since $\gamma$-radiation as well as fast neutrons gave similar results. Together, the present findings clearly emphasize the interest of this trimodal therapeutic approach to circumvent the resistance of glioblastoma cells to conventional treatments. Molecular mechanisms underlying the efficacy of such a combination remain to be analyzed.

An important feature of our investigations is the comparative effect resulting from the combination of RAD001 with high-LET particles or low-LET radiations. In radiation therapy, the former offers two main advantages over the latter for the treatment of some types of cancers (15). First, high-LET particles can be delivered with a high accuracy for normal tissue volume, due to the Braggs distribution in depth of the radiation dose. Second, unlike sparsely ionizing low-LET radiation, high-LET particles provoke clustered severe and irreparable damage in DNA $(16,17)$. As a consequence, they kill or inactivate malignant cells more effectively than conventional, photon-based RT.

Another aspect of the present study concerns the mode of cell death triggered by the triple combined treatment. It is known that in glioblastoma cells, several forms of cell death, including apoptosis (18), autophagy (19), necroptosis (20) and senescence (10) could underlie the cytotoxic response to radiation. In the present case, our results clearly indicate that apoptosis participates very little in the efficacy of the co-treatment. In contrast, in RAD001/TMZ co-treated cells, autophagy was significantly increased, but the irradiation did not reinforce its occurrence. In fact, in a previous study (13), we reported that the combination TMZ with RAD001 was able to synergize for reducing U-87 cell growth and to induce autophagy of these cells. The importance of autophagy, an important catabolic process of degradation of cellular components for eukaryotic cells in physiological as well as in pathological situations $(21,22)$ still remains debated. In radiation therapy, it is not yet established whether autophagy plays 
a protective role toward radiation or a cell death inductor function (23). The induction of autophagy has also been suggested to influence the response of glioma cells to radiation by promoting their differentiation and their radiosensitivity (24). On the other hand, whether the mechanisms underlying radiosensitization by RAD001 or more recent mechanistic target of rapamycin (mTOR) inhibitors are linked to the induction of autophagy remains questionable. In fact, many pathways involved in mTORC 1 and mTORC2, could be potentially affected by radiation (25). Actually, in a number of tumor cell lines, the inhibition of mTORC1 has been reported to decrease rather than increase the radiosensitivity of tumor cells in vitro. This was shown in HeLa, a cervical adenocarcinoma cell line following pretreatment with rapamycin followed by irradiation. However, the increased radioresistance was observed only when rapamycin was added to the cells before irradiation, indicating that mTOR inhibition may sometimes promote radioprotection (26). The balance between various factors involved in cell death, in the activation of cell survival pathways and in DNA damage repair processes could account for these differences. The latter point appears to be the most critical for determining the cell fate. Interestingly, rapamycin has been reported to suppress DSB repair (27). Thus, one may assume that when combined together, RAD001, TMZ and radiation could mutually reinforce their reciprocal action by converging towards the induction of irreversible DNA damage.

In conclusion, our results highlight the potential therapeutic value of associating a conventional chemotherapeutic agent, a molecular-targeted drug and radiation, to substantially suppress GBM cell growth. They also indicate that in the context of this triple combination, low-LET radiations are almost as efficient as high-LET radiations in producing such a growth-suppressing effect. Thus, the benefit of using high-LET radiation rather than conventional low-LET radiations may be questioned, all the more so since linear accelerators of the latest generation that are now increasingly used in anticancer centers allow for much higher precision in focusing on the tumor mass than earlier systems. Therefore, high doses of low-LET radiation, such as 6 Gy or higher, could be allocated in one fraction along with TMZ and RAD001 without severely affecting healthy surrounding tissues. Nevertheless, it would be hazardous to conclude from the present results that high-LET radiation has no role to play in the treatment of GBM. Indeed, when administered alone or associated with TMZ, high-LET radiation is more capable of suppressing malignant cell growth than low-LET radiation. Moreover, apart from their targeting advantage, they differ from low-LET radiation in their capacity to produce much more lethal damage in the critical structure of cells. Given this unique specificity, one may assume that molecular-targeted drugs other than mTOR inhibitors could be more efficiently combined with high-LET radiation. Finally, determining the types of cell death and particularly the role of autophagy induced by this trimodal treatment represents another challenge for researchers. We are currently further exploring these points.

\section{Acknowledgements}

The present study was supported in part by funds from the University of Strasbourg, France and from the Cyclotron
Resources Center of the Catholic University of Louvain, Belgium. We thank Dr Francis J. Dumont for reviewing the manuscript.

\section{References}

1. Emdad L, Qadeer ZA, Bederson LB, Kothari HP, Uzzaman M, and Germano IM: Is there a common upstream link for autophagic and apoptotic cell death in human high-grade gliomas? Neuro Oncol 13: 725-735, 2011.

2. Maucort-Boulch D, Baron MH, Pommier P, Weber DC, Mizoe JE, Rochat J, Boissel JP, Balosso J, Tsuji H and Amsallem E: Rationale for carbon ion therapy in high-grade glioma based on a review and a meta-analysis of neutron beam trials. Cancer Radiother 14: 34-41, 2010.

3. Begg AC, Stewart FA and Vens C: Strategies to improve radiotherapy with targeted drugs. Nat Rev Cancer 11: 239-253, 2011.

4. Scaringi C, Enrici RM and Minniti G: Combining molecular targeted agents and radiation therapy for malignant gliomas. Onco Targets Ther 6: 1079-1095, 2013.

5. Chinnaiyan P, Won M, Wen PY, Rojiani AM, Wendland M, Dipetrillo TA, Com BW and Mehta MP: RTOG 0913: a phase 1 study of daily everolimus (RAD001) in combination with radiation therapy and temozolomide in patients with newly diagnosed glioblastoma. Int J Radiat Oncol Biol Phys 86: 880-884, 2013.

6. Zhang M, Herion TW, Timke C, Han N, Hauser K, Weber KJ, Peschke P, Wirkner U, Lahn M and Huber PE: Trimodal glioblastoma treatment consisting of concurrent radiotherapy, temozolomide and the novel TGF- $\beta$ receptor I kinase inhibitor LY2109761. Neoplasia 13: 537-549, 2011.

7. Sarkaria JN, Galanis E, Wu W, Peller PJ, Giannini C, Brown PD, Uhm JH, McGraw S, Jaeckle KA and Buckner JC: North central cancer treatment group phase I trial N057K of everolimus (RAD001) and temozolomide in combination with radiation therapy in patients with newly diagnosed glioblastoma multiforme. Int J Radiat Oncol Biol Phys 81: 468-475, 2011.

8. Annovazzi L, Mellai M, Caldera V, Valente G, Tessitore L and Schiffer D: mTOR, S6 and AKT expression in relation to proliferation and apoptosis/autophagy in glioma. Anticancer Res 29: 3087-3094, 2009.

9. Dancey J: mTOR signaling and drug development in cancer. Nat Rev Clin Oncol 7: 209-219, 2010.

10. Lee JJ, Kim BC, Park MJ, Lee YS, Kim YN, Lee BL and Lee JS: PTEN status switches cell fate between premature senescence and apoptosis in glioma exposed to ionizing radiation. Cell Death Differ 18: 666-677, 2011.

11. Gueulette J, Slabbert JP, Bischoff P, Denis JM, Wambersie A and Jones D: Fast neutrons: Inexpensive and reliable tool to investigate high-LET particle radiobiology. Radiat Meas 45: 1414-1416, 2010.

12. Riccardi C and Nicoletti I: Analysis of apoptosis by propidium iodide staining and flow cytometry. Nat Protoc 1: 1458-1461, 2006.

13. Josset E, Burckel H, Noël G and Bischoff P: The mTOR inhibitor RAD001 potentiates autophagic cell death induced by temozolomide in a glioblastome cell line. Anticancer Res 33: 1845-1851, 2013.

14. Altmeyer A, Josset E, Denis JM, Gueulette J, Slabbert J, Mutter D, Noël G and Bischoff P: The mTOR inhibitor RAD001 augments radiation-induced growth inhibition in a hepatocellular carcinoma cell line by increasing autophagy. Int $\mathbf{J}$ Oncol 41: 1381-1386, 2012.

15. Rodriguez-Lafrasse $\mathrm{C}$ and Balosso J: From the carbon track to therapeutic efficiency of hadrontherapy. Cancer Radiother 16: 16-24, 2012 (In French).

16. Hada M and Georgakilas AG: Formation of clustered DNA damage after high-LET irradiation: a review. J Radiat Res 49: 203-210, 2008.

17. Hamada N, Imaoka T, Masunaga S, Ogata T, Okayasu R, Takahashi A, Kato TA, Kobayashi Y, Ohnishi T, Ono K, Shimada $\mathrm{Y}$ and Teshima T: Recent advances in the biology of heavy-ion cancer therapy. J Radiat Res 51: 365-383, 2010.

18. Tsuboi K, Moritake T, Tsuchida Y, Tokuuye K, Matsumura A and Ando K: Cell cycle checkpoint and apoptosis induction in glioblastoma cells and fibroblasts irradiated with carbon beam. J Radiat Res 48: 317-325, 2007. 
19. Benzina S, Altmeyer A, Malek F, Dufour P, Denis JM, Gueulette J and Bischoff P: High-LET radiation combined with oxaliplatin induce autophagy in U-87 glioblastoma cells. Cancer Lett 264: 63-70, 2008

20. Jiang YG, Peng Y and Koussougbo KS: Necroptosis: a novel therapeutic target for glioblastoma. Med Hypotheses 76: 350-352, 2011.

21. Todde V, Veenhuis M and van der Klei IJ: Autophagy: principles and significance in health and disease. Biochim Biophys Acta 1792: 3-13, 2009.

22. Hönscheid P, Datta K and Muders MH: Autophagy: detection, regulation and its role in cancer and therapy response. Int $J$ Radiat Biol: Jun 25, 2014 (Epub ahead of print). doi: 10.3109/09 553002.2014 .907932$.

23. Zois CE and Koukourakis MI: Radiation-induced autophagy in normal and cancer cells: towards novel cytoprotection and radio-sensitization policies? Autophagy 5: 442-450, 2009.
24. Zhuang W, Li B, Long L, Chen L, Huang Q and Liang Z: Induction of autophagy promotes differentiation of gliomainitiating cells and their radiosensitivity. Int J Cancer 129: 2720-2731, 2011.

25. Dumont FJ and Bischoff P: Disrupting the mTOR signaling network as a potential strategy for the enhancement of cancer radiotherapy. Curr Cancer Drug Targets 12: 899-924, 2012.

26. Bandhakavi S, Kim YM, Ro SH, Xie H, Onsongo G, Jun CB Kim DH and Griffin TJ: Quantitative nuclear proteomics identifies mTOR regulation of DNA damage response. Mol Cell Proteomics 9: 403-414, 2010.

27. Chen H, Ma Z, Vanderwaal RP, Feng Z, Gonzales-Suarez I, Wang J, Roti Roti JL, Gonzalo S and Zhang J: The mTOR inhibitor rapamycin suppresses DNA double-strand break repair. Radiat Res 175: 214-224, 2011. 